\title{
Design and Analysis of a Non-Uniform Meander RF MEMS Switch
}

\author{
C Leela Mohan ${ }^{1}$, K Ch Sri Kavya ${ }^{2}$ and K Sarat Kumar ${ }^{3}$ \\ ${ }^{1}$ Research Scholar, Dept. of ECE, Koneru Lakshmaiah Educational Foundation (Deemed to be University), \\ Green Fields, Vaddeswaram, Guntur - 522502, Andhra Pradesh, India. \\ ${ }^{2}$ Professor, Dept. of ECE, Koneru Lakshmaiah Educational Foundation (Deemed to be University), Green \\ Fields, Vaddeswaram, Guntur - 522502, Andhra Pradesh, India. \\ ${ }^{3}$ Professor, Dept. of ECE, Koneru Lakshmaiah Educational Foundation (Deemed to be University), Green \\ Fields, Vaddeswaram, Guntur - 522502, Andhra Pradesh, India. \\ E-mail: ${ }^{1}$ leelamohan416@gmail.com, ${ }^{2}$ kavya@kluniversity.in, ${ }^{3}$ kksarat@ kluniversity.in
}

\begin{abstract}
This paper aimed to design and analysis of non-uniform meander capacitive shunt RF MEMS switch. The less pull in voltage is obtained in flexure type membrane by proposed RF MEMS Switch. The selection of materials for the beam and dielectric layer is expressed in this paper and also shown the performance depends on materials utilized for the design. The high isolation of $-31.15 \mathrm{~dB}$ actuating at the pull-in voltage of $7.69 \mathrm{~V}$ with a spring constant of $3.28 \mathrm{~N} / \mathrm{m}$ produced the switch and is obtained by the optimization process. Capacitive contact switches have capability of power handling. The actuated switch state provides an excellent isolation. It shorts the ground by RF signal. MEMS technology is the integration of electrical and mechanical components on single platform i.e. substrate [10]. From the literature, various researchers have proposed
\end{abstract}

\section{Introduction}

MEMS technology presents miniaturization than other technologies like CMOS and GaAs technology. This technology presents a good electrical performance, linearity with less power Consumption. [1-4] RF MEMS is promising technology, because of superior performance; they are spread widely in wireless communications. RF switches enable switching in transmission line they use mechanical switching Classification of MEMS switches is to be done in two ways i.e. metal to metal. Capacitive contact switches. They support for high frequency applications; resistive switches are suits for low frequency application [5]. Configuration is of two types' series and shunt. Switch with shunt configuration produce improved performance. In actuated state capacitive contact was achieved by fixed -fixed switch that use metal membrane [6-9].

To address the drawbacks and to improve the different RF MEMS Switch, but still there few challenges on optimization of the Switch for best performance. The electromechanical analysis such as Upstate, Downstate capacitances and stress analysis have been carried out. The performance of the switch is analyzed by taking appropriate materials selected by Ashby's approach. These optimized dimensions are feasible to fabricate. The substrate height, material for the substrate and coplanar waveguides are used for the impendence matching. For obtaining the less pull in voltage overlapping area is to be increased.

Keywords: Isolation Loss, Insertion Loss, Meanders, Pull-In voltage, RF MEMS, Return Loss, spring constant, Switching time,

functionality, an optimization process for the switch structure is proposed based on the frequency of application which enhances the switch performance, in terms of low insertion loss, high isolation and less pull in voltage [11]. The switch dimensions are extracted through optimization using proposed method. The modified switch reduces the pull in voltage, spring constant and stiction problem, by introducing the meanders in the proposed structure. Two types of meanders i.e uniform and non-uniform, at beginning the switch uses single uniform and non-uniform meanders [12-14]. For both the switches solid mechanical analysis, electromechanical analysis and electromagnetic analysis are done. The impedance matching will be acquired to maximum power transfer with low return loss using RF MEMS switch. The high frequency ka-Band has lot of advantages comparatively with low frequency such as less interference and compact sizes [15]. 
The organization of the paper follows; in Section-2, the RF MEMS proposed Switch and its specifications. In Section-3, the theoretical parameters description of nonuniform meanders RF MEMS Switch and the materials

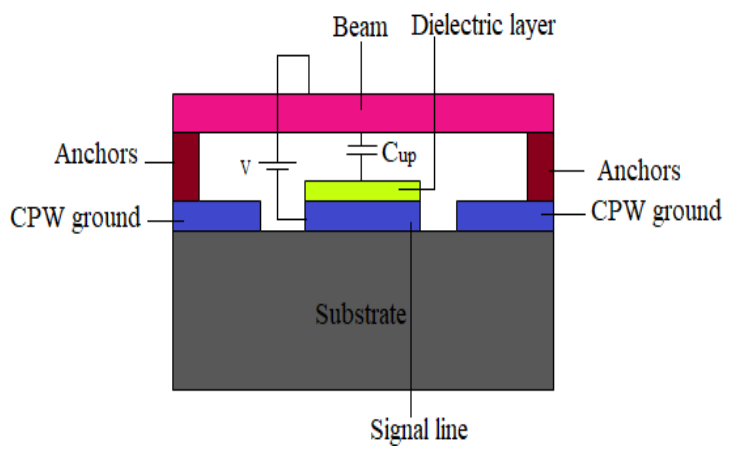

selection for the proposed switch. In Section-4, the electromechanical and electromagnetic analysis of the proposed RF MEMS Switch and comparison and in Section-V Conclusion.

1. The RF MEMS proposed switch and its specifications

\subsection{The Non-Uniform Meander RF MEMS proposed Switch structure}

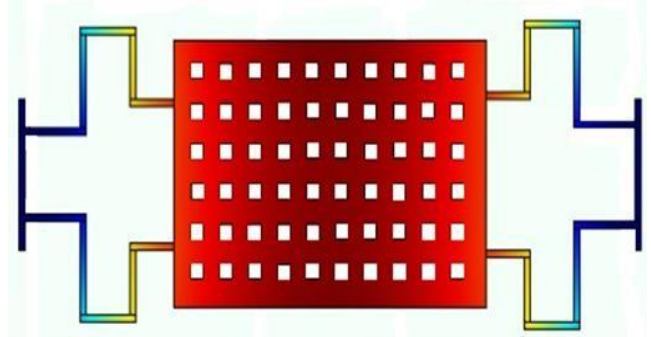

(a)

(b)

Figure 1. Schematic view of non-uniform meander proposed switch (a) side view (b)top view

\subsection{The proposed Device Dimensions}

Table 1. Dimensions of non-uniform meander switch

\begin{tabular}{|c|c|c|}
\hline Indicator & Elements & Dimensions \\
\hline $\mathrm{G} / \mathrm{S} / \mathrm{G}$ & Coplanar waveguide & $56 \mu \mathrm{m} / 95 \mu \mathrm{m} / 56 \mu \mathrm{m}$ \\
\hline $\mathrm{H}$ & Substrate Height & $400 \mu \mathrm{m}$ \\
\hline $\mathrm{W}$ & The width of membrane bridge beam & $186 \mu \mathrm{m}$ \\
\hline $\mathrm{L}$ & Length of a membrane bridge beam & $558 \mu \mathrm{m}$ \\
\hline $\mathrm{g}_{0}$ & Air gap & $3 \mu \mathrm{m}$ \\
\hline $\mathrm{t}_{\mathrm{d}}$ & Dielectric thickness & $0.2 \mu \mathrm{m}$ \\
\hline $\mathrm{As}$ & Square holes & $6 \mu \mathrm{m} \times 6 \mu \mathrm{m}$ \\
\hline $\mathrm{A}$ & Actuation area & $186 \mu \mathrm{m} \times 270 \mu \mathrm{m}$ \\
\hline
\end{tabular}

Table 2. Non uniform meander dimensions

\begin{tabular}{|c|c|c|c|}
\hline Indicator & Length & Width & Thickness \\
\hline $\mathrm{K} 1$ & $38 \mu \mathrm{m}$ & $5 \mu \mathrm{m}$ & $1.2 \mu \mathrm{m}$ \\
\hline $\mathrm{K} 2$ & $45 \mu \mathrm{m}$ & $5 \mu \mathrm{m}$ & $1.2 \mu \mathrm{m}$ \\
\hline $\mathrm{K} 3$ & $48 \mu \mathrm{m}$ & $5 \mu \mathrm{m}$ & $1.2 \mu \mathrm{m}$ \\
\hline $\mathrm{K} 4$ & $65 \mu \mathrm{m}$ & $5 \mu \mathrm{m}$ & $1.2 \mu \mathrm{m}$ \\
\hline $\mathrm{K} 5$ & $58 \mu \mathrm{m}$ & $5 \mu \mathrm{m}$ & $1.2 \mu \mathrm{m}$ \\
\hline
\end{tabular}




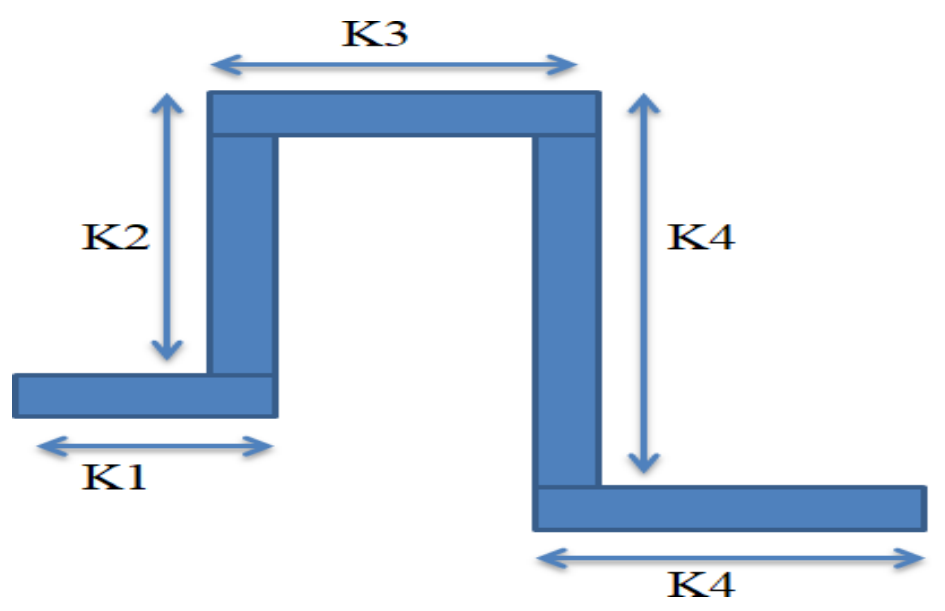

Figure 2. Schematic view of Non-Uniform Meander

\section{Theoretical parameters of uniform meander RF MEMS Switch}

\subsection{Effect of spring constant}

The Spring constant is proportional to the pull-in voltage. Low spring constant is to attain very low pullin voltage. For a fixed-fixed beam membrane spring constant is modeled using the expression

$$
k=\frac{E w t^{3}}{L^{3}}=3.2831
$$

Here Young's modulus is E, width w, thickness is $t$ and lengths are $\mathrm{L}$.

\subsection{Effect of pull in voltage}

The voltage required by the beam to pull down towards the electrode and shows minimum 2/3rd displacement in the gap between the beam and down electrode is known as pull in voltage. It can be calculated as [11]

$$
V_{p}=\sqrt{\frac{8 K g^{3}}{27 \epsilon_{0} A}} \text { Volts }=7
$$

in free space; an actuation area i.e. is the signal width and $\mathrm{w}$ is the beam width. $\mathrm{A}=\mathrm{W} \times \mathrm{w}$.

\subsection{Effect of ON or UP state capacitance (CON)}

An ON state capacitive shunt switch, If the voltage is applied to the beam the membrane gets displaced downwards and capacitance is developed between the electrode and beam. The Upstate Capacitance CON can be calculated by using

$$
C_{\text {ON }}=\sqrt{\frac{\epsilon_{0} \epsilon_{r} x y}{g+\frac{t_{d}}{\epsilon_{r}}}} \text { Farad }=10
$$

$\mathrm{x}$ - Width of the beam, $\mathrm{y}$ - Length of the beam, $\mathrm{g}$ - Gap between dielectric and beam, td - the thickness of the dielectric, er -relafiły permittivity of beam material.

\subsection{Effect of OFF or DOWN state capacitance (COFF)}

The capacitance developed by the switch when the gap vanishes due to a displacement of the beam during actuation is called down state capacitance. The obtained capacitance is termed as downstate or off state capacitance it provides a high impedance to transmit the signal to the output terminal. The downstate capacitance COFF can be calculated as

$$
C_{\text {OFF }}=\sqrt{\left.\frac{\epsilon_{0} \epsilon_{r}(\bar{x})}{t_{d}}\right)} \text { Farad }=7.03 \text { pFarads }
$$

$\mathrm{x}$ - Width of the beam, $\mathrm{y}$ - Length of the beam, g - Gap between dielectric and beam, $t_{d}-$ the thickness of the dielectric, $\varepsilon_{\mathrm{r}}$-relative permittivity of beam material.

\subsection{Effect of Capacitance Ratio (Cratio )}


It can be calculated as the ratio of the Downstate capacitance (OFF state) and Upstate capacitance (ON state) of the proposed switch.

$$
C_{\text {ratio }}=\frac{C_{O F F}}{C_{O N}}=68.25
$$

\subsection{Effect of switching time analysis}

The switching time is the time taken to change its position from one state to another state, that time taken by the device is called switching time or switching speed. It can be work fast when the switching speed of the switch would be low. It can be calculated as

$$
T_{s}=\frac{3.67 V_{p}}{V_{s} \omega_{0}} \text { Seconds }
$$

Where $\mathrm{V}_{\mathrm{P}}$-pull-in voltage, $\mathrm{V}_{\mathrm{s}}$-supply voltage, $\mathrm{V}_{\mathrm{s}}=$ $1.4 \mathrm{VP}$ and $\omega_{0}$ Represent resonant frequency. Then switching time required by the switch is $t_{s}=0.167 \mathrm{msec}$.

\subsection{Power Handling}

Power handling is an important factor in MEMS technology, the MEMS devices consume less power compared to pin diodes and semi conductor's switches. The RF MEMS shunt switch required very less power to work; mainly it depends on the switch actuation voltage. The power consumption of shunt switch can be given by

\subsection{Effect of Quality Factor}

The quality factor depends on damping coefficient, resonant frequency and the spring constant. In the proposed switch it reduces by taking the fixed fixed beam and actuation electrodes in different widths such that the air escapes between the actuation electrodes. The damping coefficient is obtained by equation

$$
b=\frac{3}{2 \pi} \frac{\mu A^{2}}{g^{3}}=0.033 \times 10^{-3}
$$
given by

Where $\mu$ is viscosity of air, A overlapping area and $g$

\subsection{Dielectric Material Selection}

gap between the electrodes. Thus, the quality factor is

$$
Q=\frac{K}{2 \pi f_{0} b}
$$

It is advantageous to have a switch with $0.5 \leq \mathrm{Q} \leq 2$. In this proposed the quality factor obtained is $\mathrm{Q}=0.55$ which is good enough to get desired switching activity of the switch.

\subsection{Substrate Material selection}

We choosen different possible suitable materials for substrate and the seperate the graph between Poisson's ratio versus young's modulus. From fig.6, the first and topmost material Si (Silicon) is having the high Young's modulus and low Poisson's ratio is selected as the substrate material. High Young's modulus material have high stiffness layer and lightly placed. The switch performance is enhanced by the impedance matching which depends on the substrate dielectric constant. Due to high resistivity, less cost and having phase velocity of silicon is selected as a substrate material. The signal loss is low because of its high dielectric constant $\mathrm{er}$ $=11.9$. The co-planar waveguide dimensions plays a prominent role in RF signal transmission which is another important one (Figure 6).

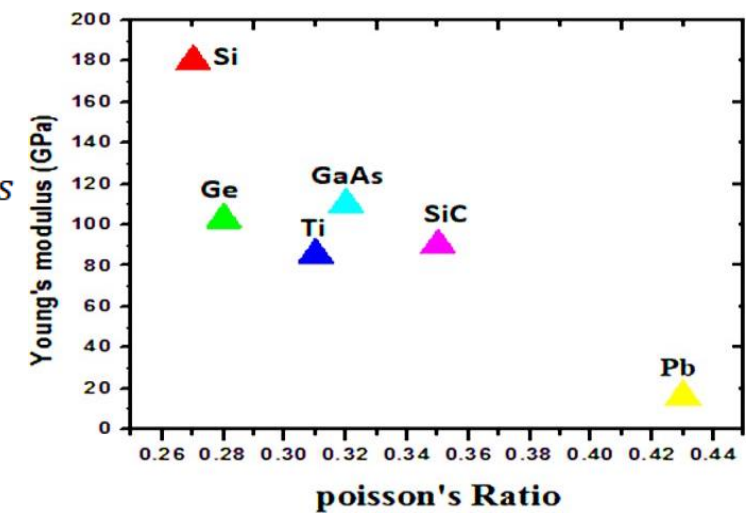

Figure 6. Substrate material selection of switch 
Table 3 Different dielectric Material Properties

\begin{tabular}{|c|c|c|c|c|}
\hline Type of Material & $\boldsymbol{\varepsilon}_{\mathbf{r}}$ & Resistivity ( $)$ & $\mathbf{1} / \boldsymbol{\varepsilon}_{\mathbf{r}}$ & $\log (\boldsymbol{\rho})$ \\
\hline $\mathrm{SiO} 2$ & 3.9 & $1.00 \mathrm{E}+14$ & 0.25641 & 14 \\
\hline $\mathrm{Si} 3 \mathrm{~N} 4$ & 7.5 & $1.00 \mathrm{E}+14$ & 0.133333 & 14 \\
\hline $\mathrm{Al} 2 \mathrm{O} 3$ & 9.8 & $1.00 \mathrm{E}+14$ & 0.102041 & 14 \\
\hline $\mathrm{AlN}$ & 8.5 & $1.00 \mathrm{E}-04$ & 0.117647 & -4 \\
\hline $\mathrm{HfO} 2$ & 25 & $1.00 \mathrm{E}+14$ & 0.04 & 14 \\
\hline
\end{tabular}

Different useful materials are fitting for the dielectric layer are considered and develop the graph against the dielectric constant and electrical resistivity. Whichever is the material is having high dielectric constant with average resistivity is chosen as a dielectric layer. $\mathrm{HfO} 2$ (Hafnium oxide) is taken as the dielectric layer because of its high dielectric constant as shown in the fig.7. The dielectric constant of the material increases the pulldown capacitance depends directly on the switch capacitance ratio and by increasing the pull-down capacitance and capacitance ratio we can easily attain the caring and stability of the switch. (Fig.7).

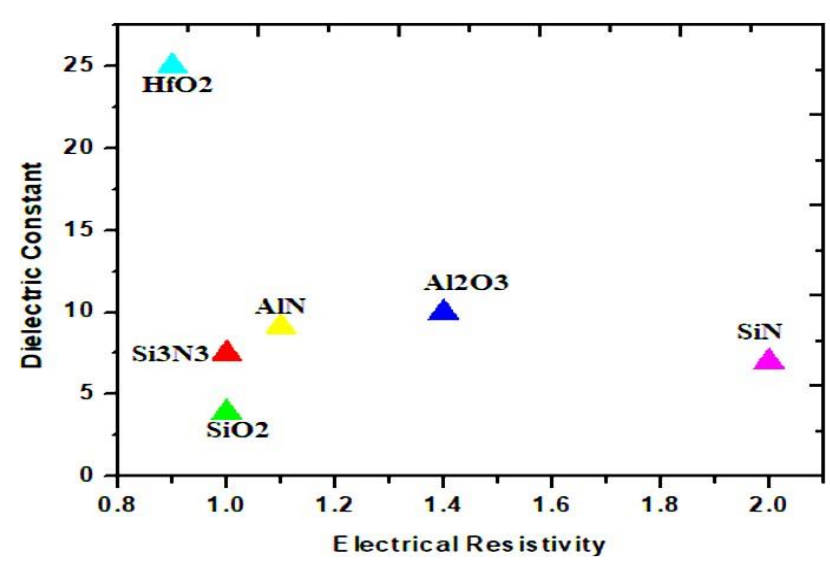

Figure 7. Dielectric material selection of switch

\subsection{Beam Material Selection}

Table 4. Different beam Material Properties

\begin{tabular}{|c|c|c|c|c|}
\hline Type of Material & E (Gpa) & rho & $\sqrt{\boldsymbol{E}}$ & $\sqrt{\boldsymbol{E} / \boldsymbol{\rho}}$ \\
\hline Gold & 79 & 19.3 & 8.88819 & 2.02318 \\
\hline Aluminum & 70 & 2.7 & 8.3666 & 5.09175 \\
\hline Platinum & 168 & 21.45 & 12.96148 & 2.7986 \\
\hline $\mathrm{Si} 3 \mathrm{~N} 4$ & 385 & 3.1 & 19.62142 & 11.14422 \\
\hline $\mathrm{Ni}$ & 200 & 8.902 & 14.14214 & 4.73992 \\
\hline $\mathrm{Si}$ & 196 & 2.3 & 14 & 9.23133 \\
\hline $\mathrm{SiO} 2$ & 73 & 2.27 & 8.544 & 5.67085 \\
\hline
\end{tabular}




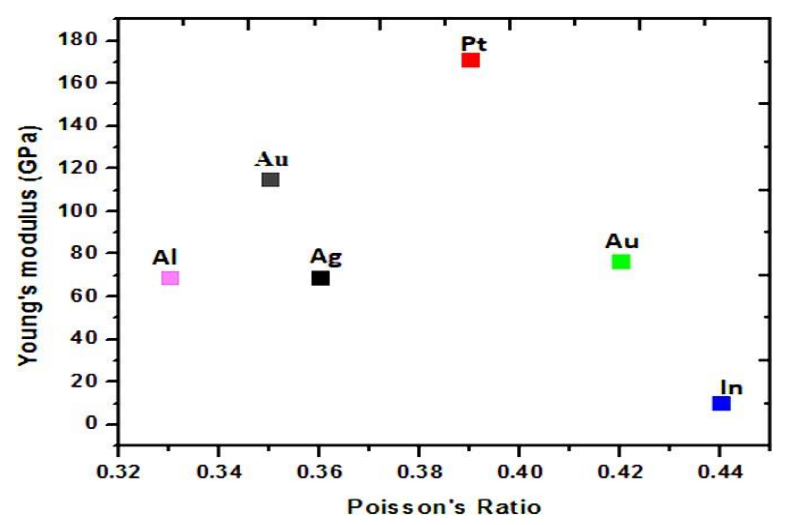

Figure 8. Beam material selections of switch

For beam material selection different suitable materials are examined and mark the graph with their indices variation against Young's modulus and Poisson's ratio. Whichever is the material have low Poisson's ratio and average young's modulus is considered as beam material which is shown in the abve fig.8. Aluminum is the best material because its Young's modulus not very high but not very low, so that good stiffness in the beam is flexible but not very much hard. So, the movement or bending of the beam is flexible. Hence, it is considered as best beam material. The $\mathrm{Au}$ (Gold) is costlier than $\mathrm{Al}$ (Aluminum), so here we preferred $\mathrm{Al}$ as the beam material (Figure 8).

Table 5.RF MEMS proposed Switch Material selection

\begin{tabular}{|l|l|}
\hline \multicolumn{1}{|c|}{ Selection } & \multicolumn{1}{c|}{ Type of Material } \\
\hline Substrate & Silicon(Si) \\
\hline Coplanar Wave Guide & Aluminum(Al) \\
\hline Dielectric Layer & Hafnium oxide( $\left.\mathrm{HfO}_{2}\right)$ \\
\hline Anchors & Aluminum(Al) \\
\hline Fixed Fixed Beam & Aluminum(Al) \\
\hline
\end{tabular}

\section{Results and Discussions}

\subsection{Non-Uniform Meander Switch Electromechanical Analysis}

Case i) Change of beam materials

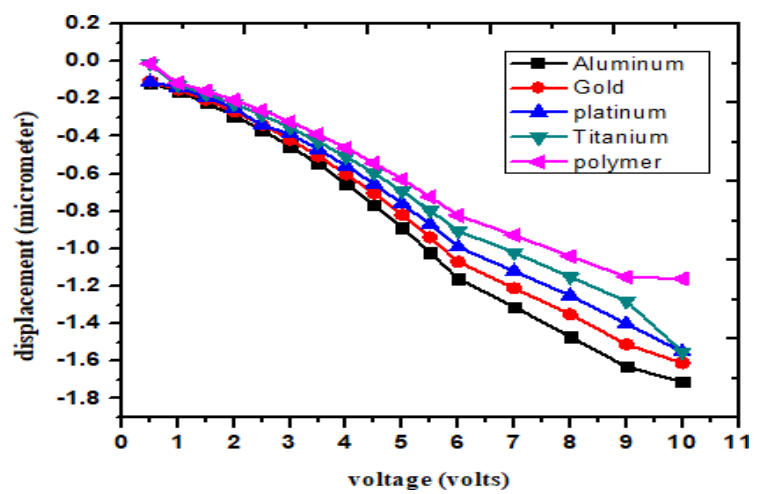

Figure 9. Voltage Vs displacement by changing different materials 
Case ii) Change of gaps

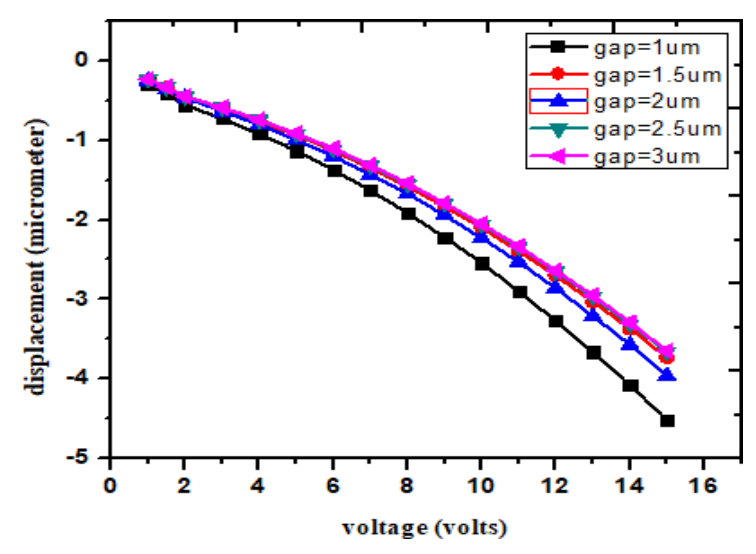

Figure 10. Voltage Vs displacement for distinct gaps

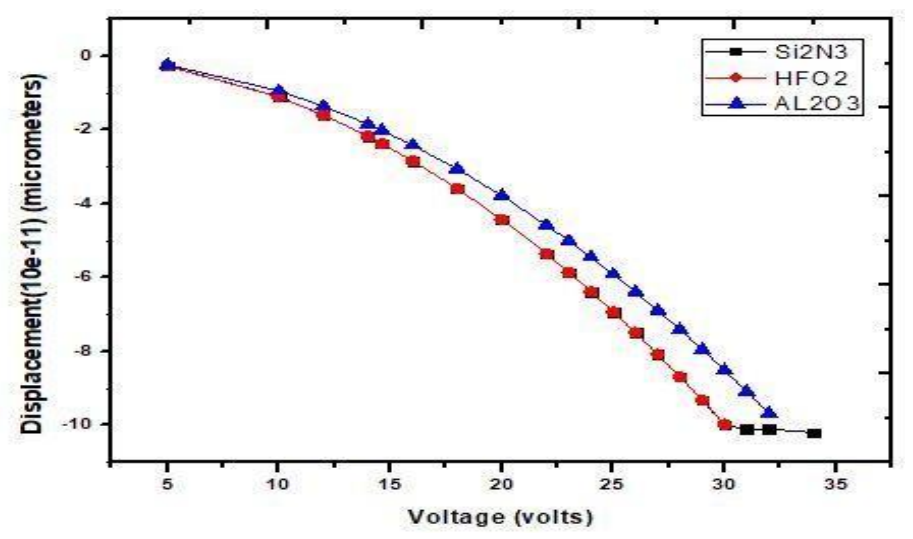

Case iii) Exchange of distinct dielectric materials

Figure 11. Voltage Vs displacement by changing dielectric materials

Pull in voltage:

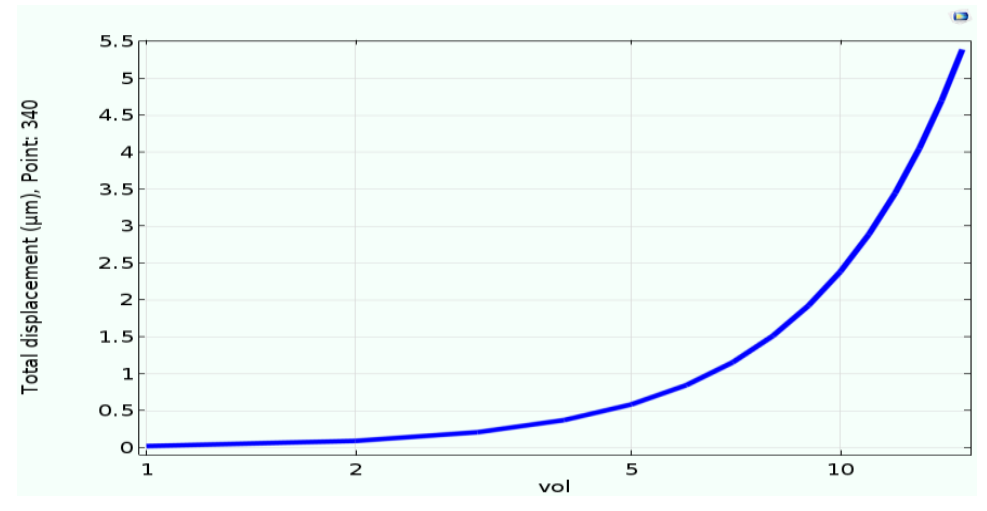

Figure 12. Voltage Vs displacement through simulation 


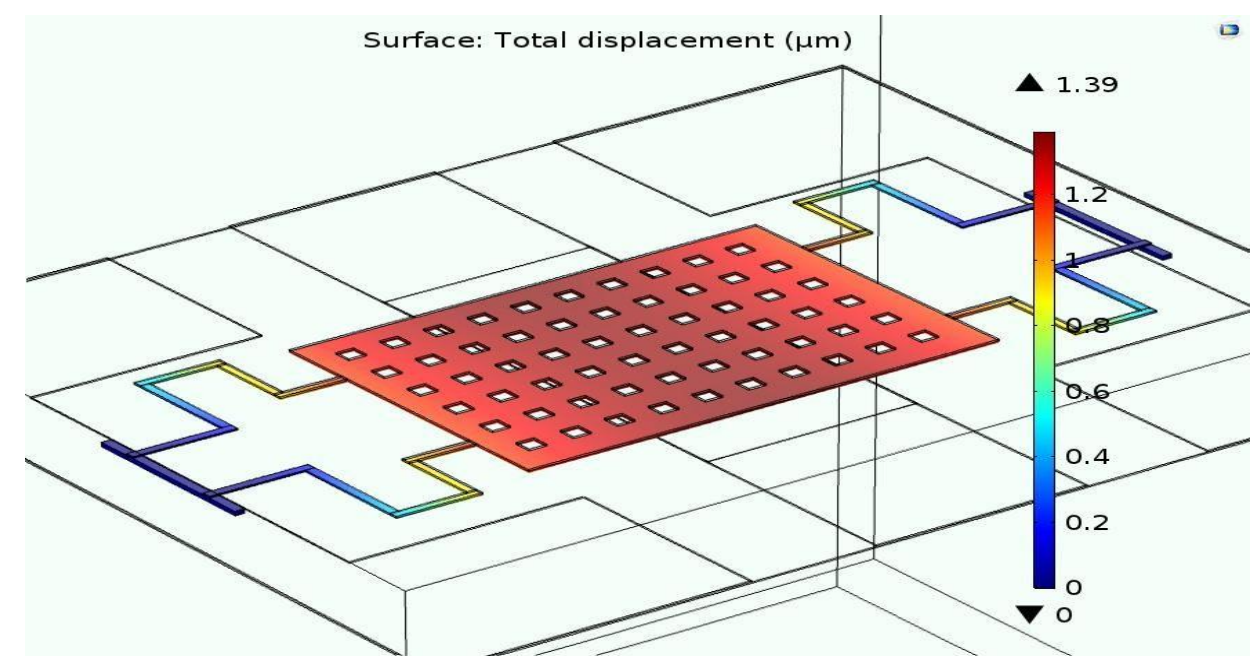

Figure 13. View of total displacement for pull in voltage through FEM tool

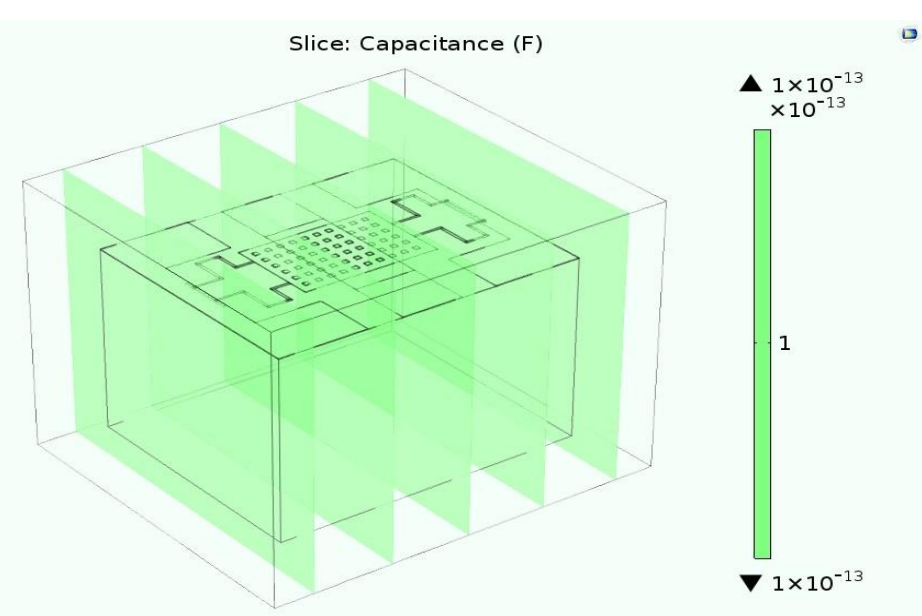

Figure 14. Simulated ON state capacitance
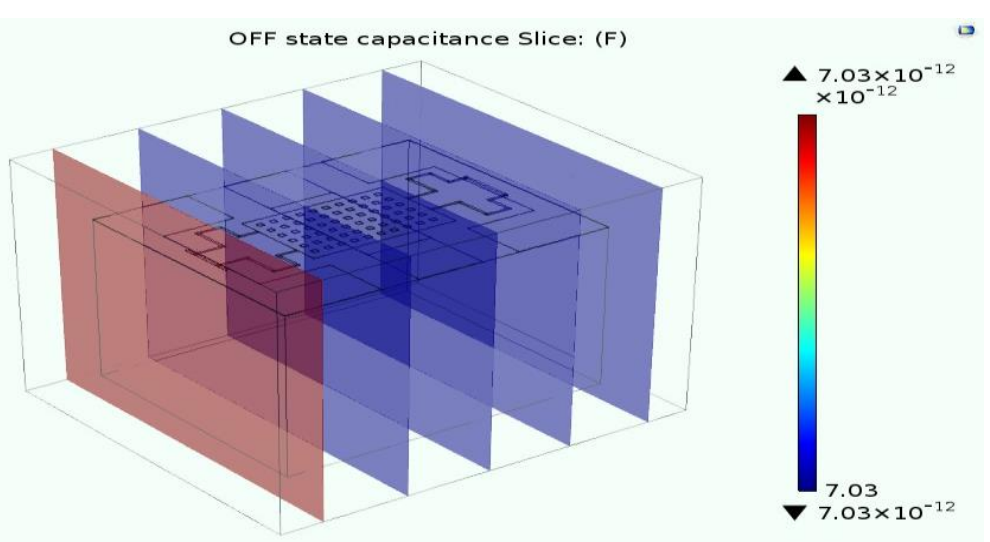

Figure 15. Simulated OFF state capacitance 


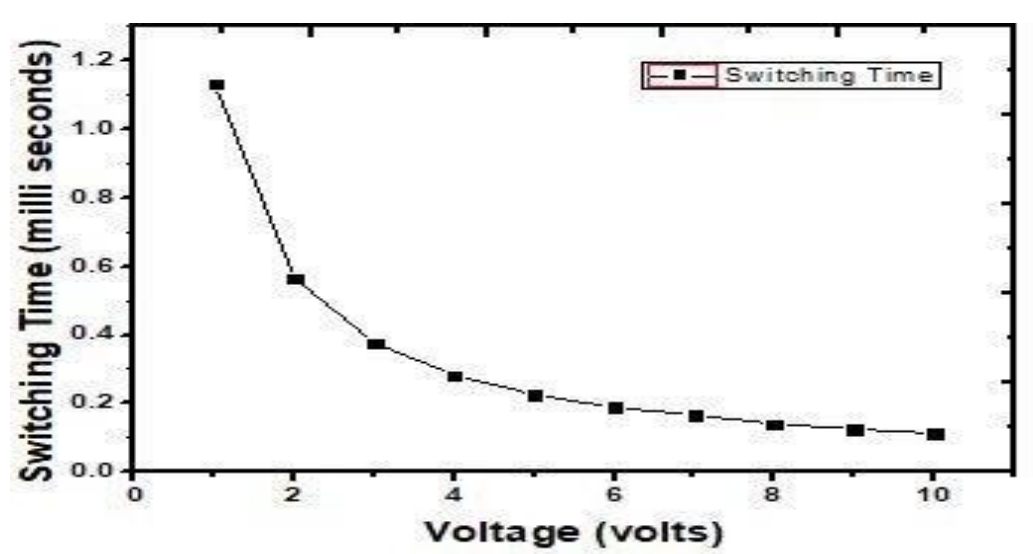

Figure 16. Switching time for non-uniform meander switch

\subsection{Stress Analysis}

Aluminum is chosen as the beam material. The aluminum can exhibit $1.78 \mathrm{E}-5 \mathrm{~Pa}$ of stress, for maximum force $1.9606 \mathrm{E}$ $6 \mathrm{~N}$.

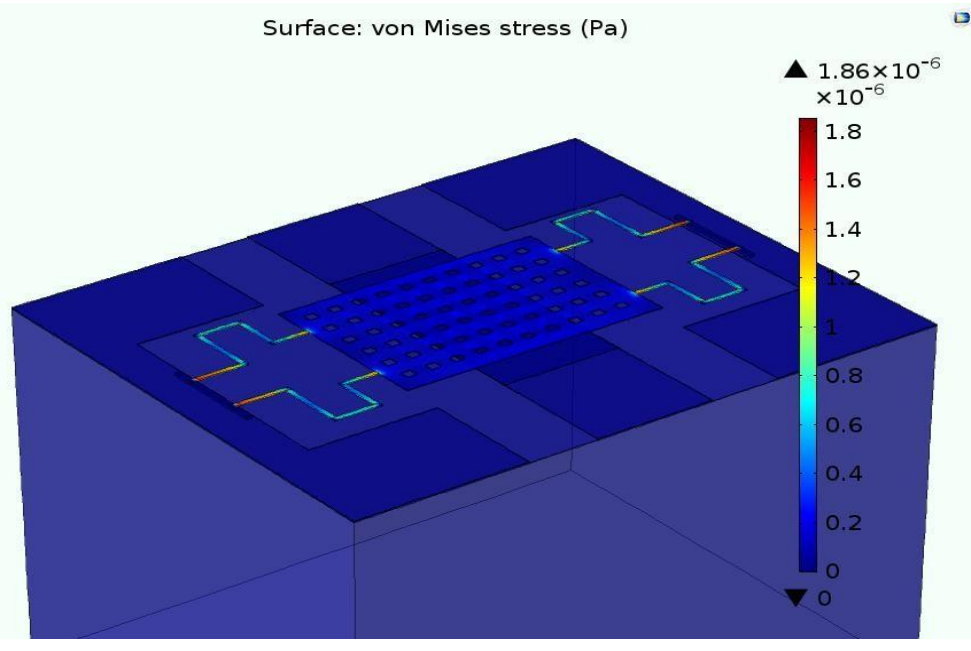

Figure 17. Stress distribution

\subsection{Non-Uniform Meander Switch Electromagnetic Analysis}

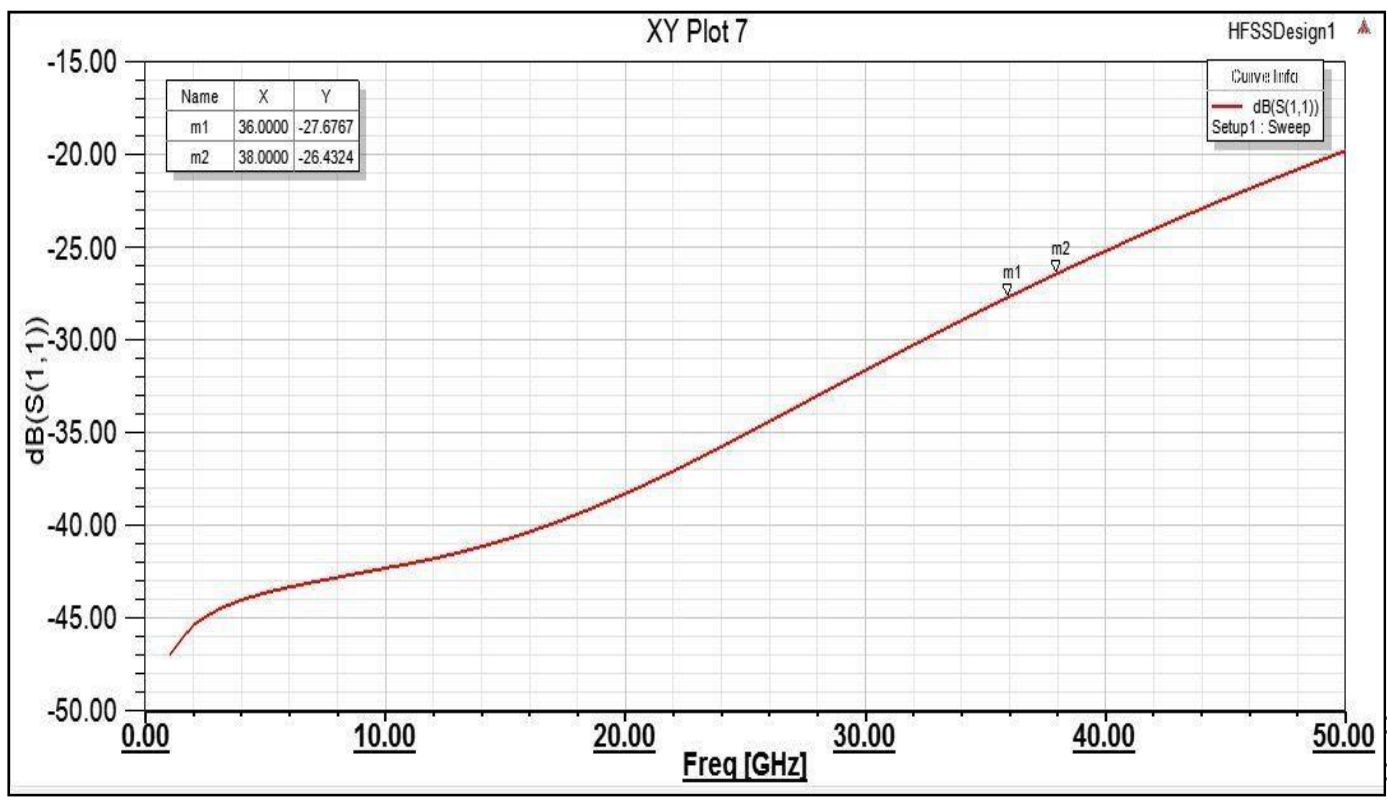


Figure18. Non-Uniform meander switch Return loss

Return Loss: It is existing because of impedance misalliance between the circuits.

Insertion loss: Other than frequency selection, critical to test insertion loss. At high frequencies power is expansive. So electromechanical switches provide lowest possible loss.

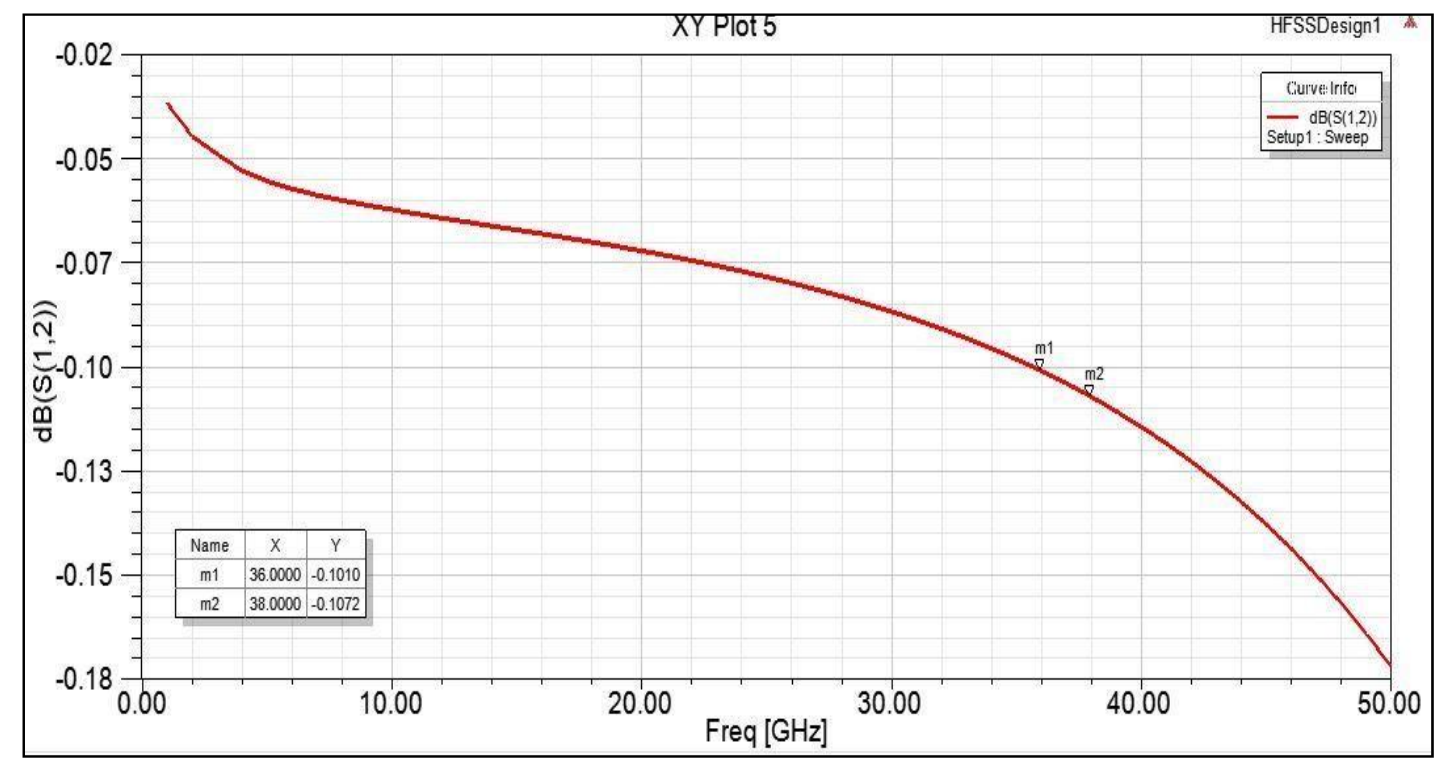

Figure 19. Non-Uniform meander switch Insertion loss

Isolation loss: It is the strength of attenuation from an

unwanted signal detected at the port of interest. It is important at higher frequencies.

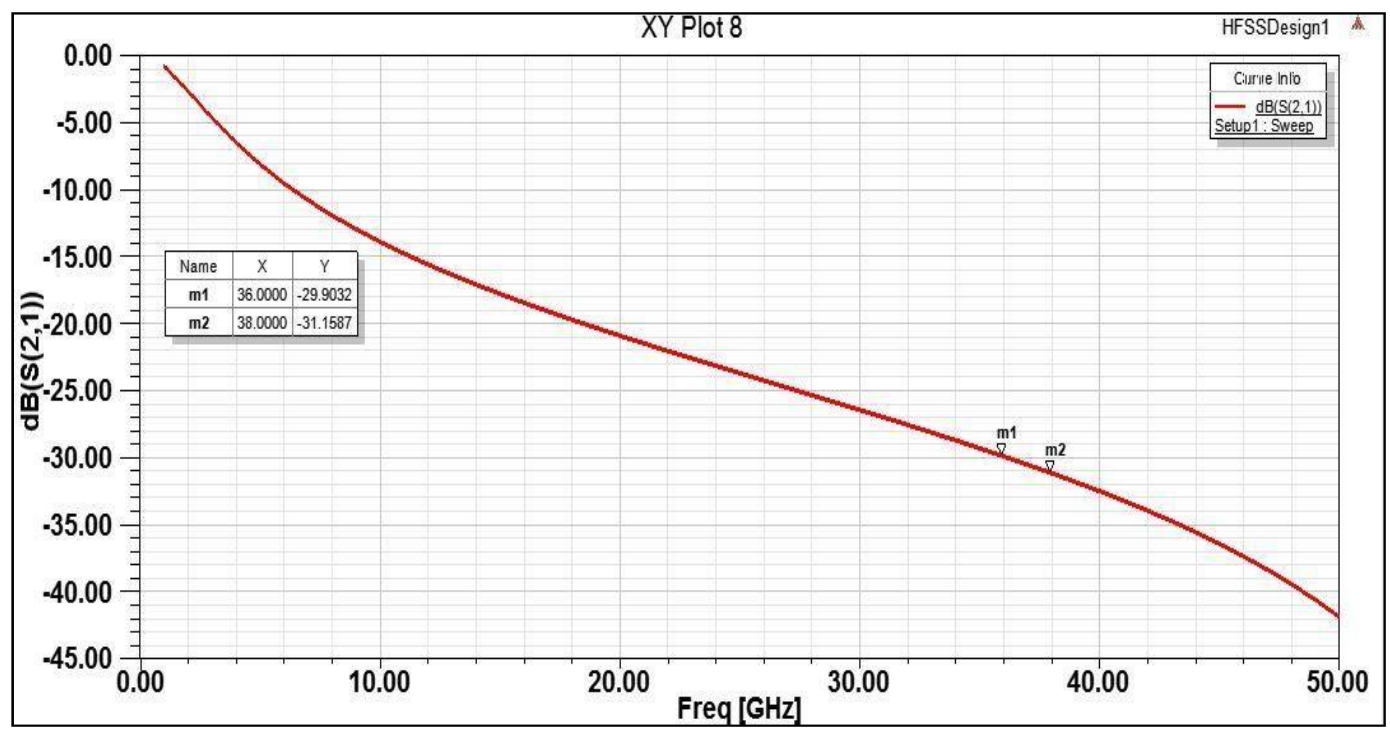

Figure 20 Non-Uniform meander switch Isolation loss 


\subsection{Comparison}

Table 6. Uniform meander switch and Non Uniform meander switch Comparison

\begin{tabular}{|c|c|c|}
\hline Parameter & $\begin{array}{l}\text { Uniform meander RF } \\
\text { MEMS Shunt Switch }\end{array}$ & $\begin{array}{l}\text { Non uniform meander RF } \\
\text { MEMS shunt Switch }\end{array}$ \\
\hline Spring constant & $3.5887 \mathrm{~N} / \mathrm{m}$ & $3.2831 \mathrm{~N} / \mathrm{m}$ \\
\hline Pull in voltage & 8.06 Volts & 7.69Volts \\
\hline Switching Time & $0.14 \mathrm{msec}$ & $0.467 \mathrm{msec}$ \\
\hline Up or ON capacitance & $103 \mathrm{fF}$ & $103 \mathrm{fF}$ \\
\hline Down or OFF capacitance & $7.03 \mathrm{pF}$ & $7.03 \mathrm{pF}$ \\
\hline Capacitance ratio & 68.25 & 68.25 \\
\hline Force & $1.9606 \mathrm{E}-6 \mathrm{~N}$ & $1.9606 \mathrm{E}-6 \mathrm{~N}$ \\
\hline Stress & $1.78 \mathrm{E}-5 \mathrm{~N} / \mathrm{m}^{2}$ & $1.86 \mathrm{E}-6 \mathrm{~N} / \mathrm{m}^{2}$ \\
\hline Quality factor & 0.55 & 0.55 \\
\hline Power Handling & $1.299 \mu$ watts & $1.182 \mu$ watts \\
\hline Return loss & $-13.86 \mathrm{~dB}$ & $-27.67 \mathrm{~dB}$ \\
\hline Insertion loss & $-0.44 \mathrm{~dB}$ & $-0.1010 \mathrm{~dB}$ \\
\hline Isolation & $-31.56 \mathrm{~dB}$ & $-31.15 \mathrm{~dB}$ \\
\hline Antenna Return loss & $-17.62 \mathrm{~dB}$ & $-27.26 \mathrm{~dB}$ \\
\hline Total gain of Antenna & $8.055 \mathrm{~dB}$ & $6.952 \mathrm{~dB}$ \\
\hline VSWR of antenna & $0.3348 \mathrm{~dB}$ & $0.2918 \mathrm{~dB}$ \\
\hline
\end{tabular}

\section{Conclusion}

In this paper, an optimization model is proposed, and switch is operated at $35 \mathrm{GHz}$ which is fabricated by Chen lei chu. The fabricated switch dimensions are modified using the optimization process and existing results comparing with proposed performance results. The optimization yields high-performance characteristics such as low pull in voltage $9.36 \mathrm{~V}$ and isolation $-29 \mathrm{~dB}$ than the fabricated switch. Hence the optimization process is carrying out to design a fixedfixed capacitive shunt switch at $38 \mathrm{GHz}$ operating frequency. The switch produces high isolation of $31.15 \mathrm{~dB}$ actuating at the pull-in voltage of $7.69 \mathrm{~V}$ with a spring constant of $3.28 \mathrm{~N} / \mathrm{m}$ which is obtained by the optimization process (Fig.9 to Fig 17).
The proposed RF MEMS switch can be efficiently used as the switch element between the patches of the antenna for re-configurability at high frequencies and can be utilized in future $5 \mathrm{G}$ communication applications.

\section{References}

[1] G. M. Rebeiz, (2003) RF MEMS Theory, Design and Technology John Wiley \& Sons, USA

[2] G. M. Rebeiz, and J. B. Muldavin (2000) IEEE Trans. Microw. Theory Tech., "High-Isolation CPW MEMS Shunt Switches -Part-2", 48, 1053.

[3] C. L. Gold- smith, D. Denniston, E. Eshelman, 
S. Chen, and Z. J. Yao, et al., (1999) " Micro machined Low-Loss Microwave Switches", IEEE J. Microelectromech. Systems, 8, 129

[4] C. T. Nguyen, L. P. B. Katehi and S. P. Pacheco, (2000) "Design of Low Actuation Voltage RF MEMS Switch", Microwave Symposium Digest. IEEE MTT-S International (USA)

[5] Chenlei Chu1, Hao Yan1, Xiaoping Liao1, (2017)" Ka-band RF MEMS capacitive switch with low loss, high isolation, long-term reliability and high-power handling based on GaAs MMIC", IET Microw. Antennas Propag., Vol. 11 No. 6, pp. 942-948.

[6] Elliott Brown, James F. Harvey, Linda P.B. Katehi, (2002) "MEMS and Si Micromachined circuits for high frequency applications", IEEE Trans. Microw. Theory Tech, vol. 50 No 3, pp. 858-866.

[7] Lee, B., Park, J., Roh, W., Seol, J.-Y., et.al, (2014) "Millimeter wave beamforming as an enabling technology for 5G cellular communications: theoretical feasibility and prototype results"., IEEE Communications Magazine, vol. 52 No 2, pp. 106-113.

[8] S.D. Keller, (June 2008) "Coplanar Waveguide Slot-coupled Ka-band Patch Antenna for Integration with Wafer-scale Beam-steering MEMS Control Board", ACES JOURNAL, Vol. 23, No. 2, pp. 1054-4887.

[9] Rahim, M. K. A., Hamid, M. R., Samsuri, N. A., et.al, (2016) "Frequency reconfigurable antenna for future wireless communication system", 46th European Microwave Conference (EuMC), London, UK,. 4-6.

[10] Baek, K.-H., Hong, W., \& Ko, S., (2017) "Millimeter-Wave 5G Antennas for Smartphones: Overview and Experimental Demonstration", IEEE Transactions on Antennas and Propagation", Vol. 65 No. (12), pp. 6250-6261.

[11] Ahmed M. Montaser, Korany R. Mahmoud, (2017) "Design of dual-band circularly polarized array antenna package for 5G mobile terminals with beam-steering capabilities", IET Microwaves, Antennas \& Propagation, Vol. 12 No. 1, pp. 29-3.

[12] Akin, T., Demirel, K., Demir, S., \& Yazgan,
E., et al., ( 2016) "A New TemperatureTolerant RF MEMS Switch Structure Design and Fabrication for Ka-Band Applications", Journal of Microelectromechanical Systems, Vol. 25 No. 1, pp. 60-68.

[13] Ganji, B. A., \& Molaei, S., (2016) "Design and simulation of a novel RF MEMS shunt capacitive switch with low actuation voltage and high isolation", Microsystem Technologies, vol. 23 No. 6, pp. 1907-1912.

[14] Ashok Kumar, P. A., Sravani, K. G., (2018) "Performance analysis of series: shunt configuration-based RF MEMS switch for satellite communication applications." Microsystem Technologies, doi:10.1007/s00542-018-3907-1.

[15] Kurmendra, Osor Pertin, (July 2018)" Pull-involtage and RF analysis of MEMS based high performance capacitive shunt switch", Microelectronics Journal, Vol. 77, Pp. 5-15. 